\title{
Correction to: Economic Low-Carbon Clean Dispatching of Power System Containing P2G Considering the Comprehensive Influence of Multi-Price Factor
}

\author{
Dai Cui ${ }^{1,2} \cdot$ Weichun $\mathrm{Ge}^{1,2} \cdot$ Wenguang Zhao ${ }^{3}$ (1) Feng Jiang $^{2} \cdot$ Yushi Zhang $^{2}$
}

Published online: 22 September 2021

(c) The Korean Institute of Electrical Engineers 2021

\section{Correction to: \\ Journal of Electrical Engineering \& Technology https://doi.org/10.1007/s42835-021-00877-4}

Due to an unfortunate oversight during the correction process, Wenguang Zhao has been affiliated to a wrong institution. It should read:

Wenguang Zhao ${ }^{3}$

${ }^{3}$ Department of Dezhou Power Supply Company, State Grid Shandong Electric Power Co. Ltd, Dezhou, China

The original article has been corrected.
Publisher's Note Springer Nature remains neutral with regard to jurisdictional claims in published maps and institutional affiliations.

The original article can be found online at https://doi.org/10.1007/ s42835-021-00877-4.

Wenguang Zhao

zhaowenguang2020@126.com

1 Department of Electrical and Electronic Engineering, Shenyang University of Technology, Shenyang, China

2 State Grid Liaoning Electric Power Co. Ltd, Shenyang, China

3 Department of Dezhou Power Supply Company, State Grid Shandong Electric Power Co. Ltd, Dezhou, China 